\title{
Prevention and Treatment of Bone Disease in Systemic Lupus Erythematosus
}

\author{
Tracy Lin, $M D^{1, *}$ \\ Jennifer Grossman, $M D^{2}$
}

\author{
Address \\ *,1Department of Medicine, University of California, Los Angeles, 1000 Veteran \\ Ave Rm 32-59 UCLA, Los Angeles, CA, 90095, USA \\ Email: tracyylin@mednet.ucla.edu \\ ${ }^{2}$ Department of Rheumatology, University of California, Los Angeles, 1000 Veteran \\ Ave Rm 32-59, UCLA, Los Angeles, CA, 90095, USA
}

Published online: 2 February 2016

(C) Springer International Publishing AG 2016

This article is part of the Topical Collection on Lupus

Keywords Osteoporosis · Lupus · Glucocorticoid - Bone mineral density · Treatment

\section{Opinion statement}

Systemic lupus erythematosus (SLE), an autoimmune chronic inflammatory disease, can be associated with significant morbidity and mortality of which bone disease such as osteoporosis is a contributor. Patients with SLE are at risk for low bone mineral density (BMD) due to a variety of reasons including inflammation, glucocorticoid use, vitamin D deficiency, premature ovarian failure, increased damage, and traditional risk factors such as age and gender. With better treatments for SLE, survival has improved; therefore, complications from morbidity including osteoporosis need better prevention and treatment strategies. In SLE patients with osteoporosis or those on glucocorticoids who meet guidelines for therapeutic intervention, we prefer bisphosphonates as first-line therapy for most patients. They have proven efficacy in increasing BMD and decreasing fracture risk, known safety profiles, and have a favorable cost-effectiveness profile. The newer agents, teriparatide and denosumab, have not only demonstrated improvement in BMD but also decreased risk of fracture. We typically recommend these medications for some high-risk populations, those who have failed bisphosphonate therapy or those who are intolerant of oral bisphosphonates. Estrogen-containing drugs are not recommended for first-line prevention and treatment of osteoporosis given the elevated risk of cardiovascular disease. Calcitonin has also been used in osteoporosis; however, the bisphosphonates and newer drugs have proven to be more efficacious. Supplementation with calcium and vitamin $D$ is recommended in particular with those patients who are vitamin $D$ deficient and those on glucocorticoids, although data documenting fracture prevention with this strategy is limited. Therapeutic strategies for premenopausal women of child-bearing 
potential remain controversial because of limited data about safety in subsequent pregnancies. Decisions for these patients need to be made on a case by case basis weighing the risks and benefits to the individual patient. Future therapies targeting different mechanisms within bone resorption and formation are currently under investigation and will significantly add to our limited armamentarium.

\section{Introduction}

Systemic lupus erythematosus is an autoimmune disease that causes chronic inflammation affecting multiple organ systems $[1,2]$. As patients with systemic lupus erythematosus (SLE) live longer, special attention to morbidity from disease complications is needed $[3,4]$. Damage scores such as the Systemic Lupus International Collaborating Clinics (SLICC) Damage Index evaluate morbidity in SLE by system, one of which is bonerelated disease complications including osteoporosis with minimal trauma fracture, vertebral collapse, and avascular necrosis [5]. Glucocorticoid use contributes to these complications which place patients at risk for glucocorticoid-induced osteoporosis (GIOP) and avascular necrosis [6]. Osteoporosis has been associated with increased chronic pain affecting up to $85 \%$ of patients with osteoporosis [7]. Patients with osteoporosis who suffer hip fractures are also at increased risk for death $[8$, 9]. Therefore, osteoporosis and fragility fractures are serious complications that can arise in the SLE population and require special attention.

Osteoporosis is a skeletal disorder characterized by low bone mass and deterioration of bone tissue microarchitecture causing bone fragility and elevated risk for fractures $[1,3,10]$. Osteoporosis is defined by a bone mineral density (BMD) T-score of less than 2.5 SD below the mean reference or fracture from minimal trauma, while osteopenia is BMD T-score less than $1 \mathrm{SD}$ below the mean reference $[3,10]$. Numerous studies have examined the prevalence of osteopenia and osteoporosis in SLE. In cross-sectional studies, osteopenia prevalence ranges from 11 to $62 \%$ (lumbar) [11, 12] and 6 to $74 \%$ (hip) $[13,14]$, while osteoporosis ranges from 4 to $42 \%$ (lumbar) [14, 15] and 3 to $42 \%$ (hip) $[13,14]$. The wide range of prevalence between studies is likely due to ethnicity, age, sex, varying study designs, disease severity, glucocorticoid use, and disease duration $[2,3,15,16]$.

The etiology for reduction in BMD in SLE is secondary to a variety of reasons and mechanisms. Traditional risk factors such as age, sex, and ethnicity play a role; however, it has been shown that the disease itself is associated with low BMD $[2,17]$. Tang et al. [17] studied 30 Asian patients with SLE with a mean age of 46 on long-term glucocorticoids and 30 Asian patients with SLE not on glucocorticoids (defined as no steroids in the last 10 years prior to study entry or never taken steroids) compared to 60 healthy controls. They found that both groups of SLE patients had significantly decreased BMD compared to controls. No difference was seen between the SLE groups taking glucocorticoids and no glucocorticoids. Sun et al. [2] studied 119 untreated Chinese female SLE patients and measured BMD to determine risk factors associated with low bone density. They found an incidence of $31.1 \%$ with osteopenia and $8.5 \%$ with osteoporosis. Although the study did not have a control group, the patients were untreated, and therefore not on glucocorticoids, suggesting that SLE itself has an effect on low BMD. Increased damage as measured by the SLICC Damage Index has been correlated with low BMD as well [18].

Vitamin D deficiency has also been associated with low BMD in SLE. Jacobs et al. followed 126 SLE patients over 6 years and assessed variables associated with low BMD in SLE [19•]. They found that low baseline 25hydroxyvitamin D levels were significantly associated with decreased spine BMD. Premature menopause has also been identified as a risk factor for fracture in the SLE population. One study found that patients with premature menopause had a higher Fracture Risk Assessment Tool (FRAX) [20] 10-year fracture risk compared to healthy age-matched controls $[21 \bullet]$.

Glucocorticoid use is a well-known risk factor for osteoporosis in the general population with doses above $7.5 \mathrm{mg} /$ day significantly associated with increased risk of non-vertebral and vertebral fractures compared to $2.5 \mathrm{mg} /$ day [22]. In SLE, the results in studies evaluating the relationship between glucocorticoids and osteoporosis have been variable. Most studies have demonstrated an association with steroids and osteoporosis in SLE $[6,11-13,19 \bullet]$, while others have failed to find similar 
results $[18,23]$. Although these findings suggest that glucocorticoids are not the only mechanism for low BMD in SLE patient, GIOP remains a serious problem for SLE patients. In 2010, the American College of Rheumatology (ACR) published guidelines for the preven- tion and treatment of GIOP, which are currently being updated [24]. Current treatment options for low BMD in SLE patients include calcium and vitamin D supplementation, calcitonin, bisphosphonates, denosumab, and teriparatide, which will be explored in this article.

\section{Treatment}

\section{Diet and Lifestyle}

- Certain lifestyle changes should be implemented in SLE patients to assist with bone health. Most of these are not specific to bone health in SLE patients but are applicable to patients at risk for low bone mass in general. Weight is viewed as a modifiable risk factor to maintain normal body mass index $[25,26]$. Weight-bearing exercise has been shown to increase BMD in multiple studies as seen in a 2002 Cochrane review [27] as well as lower fracture risk in the healthy population [28]. While most studies on the effect of exercise on bone health have not been done in SLE, Kipen et al. [29] followed BMD over 3 years in 32 premenopausal SLE patients, and 21 of the study participants were exposed to glucocorticoids during the study. They found that among participants taking glucocorticoids, exercise was protective of femoral neck BMD loss.

- It is recommended by multiple guidelines including the ACR to reduce alcohol consumption and quit smoking [10, 24]. Smoking has been associated with higher fracture risk and lower BMD [30-32]. The data behind osteoporosis and alcohol use is not as strong with some studies, actually suggesting a positive correlation with BMD with low to moderate alcohol consumption $[33,34]$. The EPIC study did not show a correlation between lifetime alcohol use and BMD; however, the group with heaviest alcohol use had lower BMD [35]. Alcohol consumption is also a variable in the World Health Organization's (WHO) FRAX to evaluate the fracture risk in patients [20]. Therefore, experts still recommend minimizing alcohol use.

- Calcium and Vitamin D

Calcium and vitamin D play a role in bone health, and most guidelines have recommended their supplementation [24]. Vitamin D deficiency (less than $20 \mathrm{ng} / \mathrm{ml}$ ) is common in SLE with a prevalence between 4 and $54 \%$ and insufficiency (less than $30 \mathrm{ng} / \mathrm{ml}$ ) prevalence up to $96 \%$ $[36 \bullet, 37]$. The cause is multifactorial including renal insufficiency; sun avoidance; diligent use of sunscreen; antivitamin D antibodies; and medications including antimalarials, antiepileptics, and glucocorticoids $[36 \bullet$ 37]. Studies on chronic steroid therapy that included SLE 
patients have suggested that vitamin $\mathrm{D}$ and calcium supplementation may have a small effect on BMD both in prevention and increased BMD early in the disease process (see Table 1) [38, 39]. Also, as mentioned above, low vitamin D level is a risk factor for low BMD in SLE patients [19•]. In the ACR recommendations for the prevention and treatment of glucocorticoid-induced osteoporosis, target vitamin D levels are to achieve "therapeutic" levels or supplementation with doses of 800$1000 \mathrm{IU} /$ day [24]. Other expert reviews have set 25 hydroxyvitamin D levels to greater than or equal to $30 \mathrm{ng} / \mathrm{ml}$ as a target $[36 \bullet, 37,40]$. In light of these recommendations, it is important to consider the ushaped association between calcium intake and cardiovascular mortality found by Wang et al [41]. Compared to those with a daily dietary calcium intake of $800 \mathrm{mg} /$ day, those with daily intakes of $500 \mathrm{mg} /$ day or greater than $1200 \mathrm{mg} /$ day were significantly associated with elevated risk of cardiovascular death. Additionally, a meta-analysis by Bolland et al. showed a $30 \%$ increased incidence of myocardial infarction with calcium supplementation compared to placebo [42]. Of note, this meta-analysis did not include concomitant vitamin D supplementation nor patients taking glucocorticoids (which has an effect on calcium absorption in the intestines), and a few of the articles had self-reported cardiovascular outcomes. It is also important to note that calcium and vitamin D supplementation was used in clinical trials evaluating the efficacy of prescription medications. In conclusion, weighing the benefits of calcium intake with the risks, it would be best for the recommended calcium intake to be obtained from dietary sources if possible using supplementation when dietary calcium is inadequate.

- Hormonal Therapies Hormonal therapy such as estrogen, selective estrogen receptor modulators (SERMs), and dehydroepiandrosterone (DHEA) have been evaluated in studies for the treatment of low BMD. Bhattoa et al. [43] compared transdermal estrogen patch to placebo for BMD and bone turnover markers for postmenopausal SLE patients with osteopenia. They found an increase in lumbar BMD and decrease in bone turnover markers in the intervention group. However, the study had a high dropout rate; therefore, the authors concluded that only certain patients in a high-risk group would benefit. Another study examined hormone replacement therapy (HRT) compared to calcitriol in SLE patients with ovarian failure and again found an increase in lumbar spine BMD but no change at the hip or radius [44]. Neither study detected differences in SLE disease activity or flares. However, although these studies had favorable results using HRT on osteoporosis in SLE, HRT is associated with increased risk of cardiovascular disease (CVD) and stroke among healthy postmenopausal women as demonstrated in the Women's Health Initiative (WHI) trial [45]. Since patients with SLE are at increased risk of CVD, HRT is not recommended for prevention and treatment of low $\mathrm{BMD}$ as better options for the prevention and treatment of osteoporosis in lupus exist. 


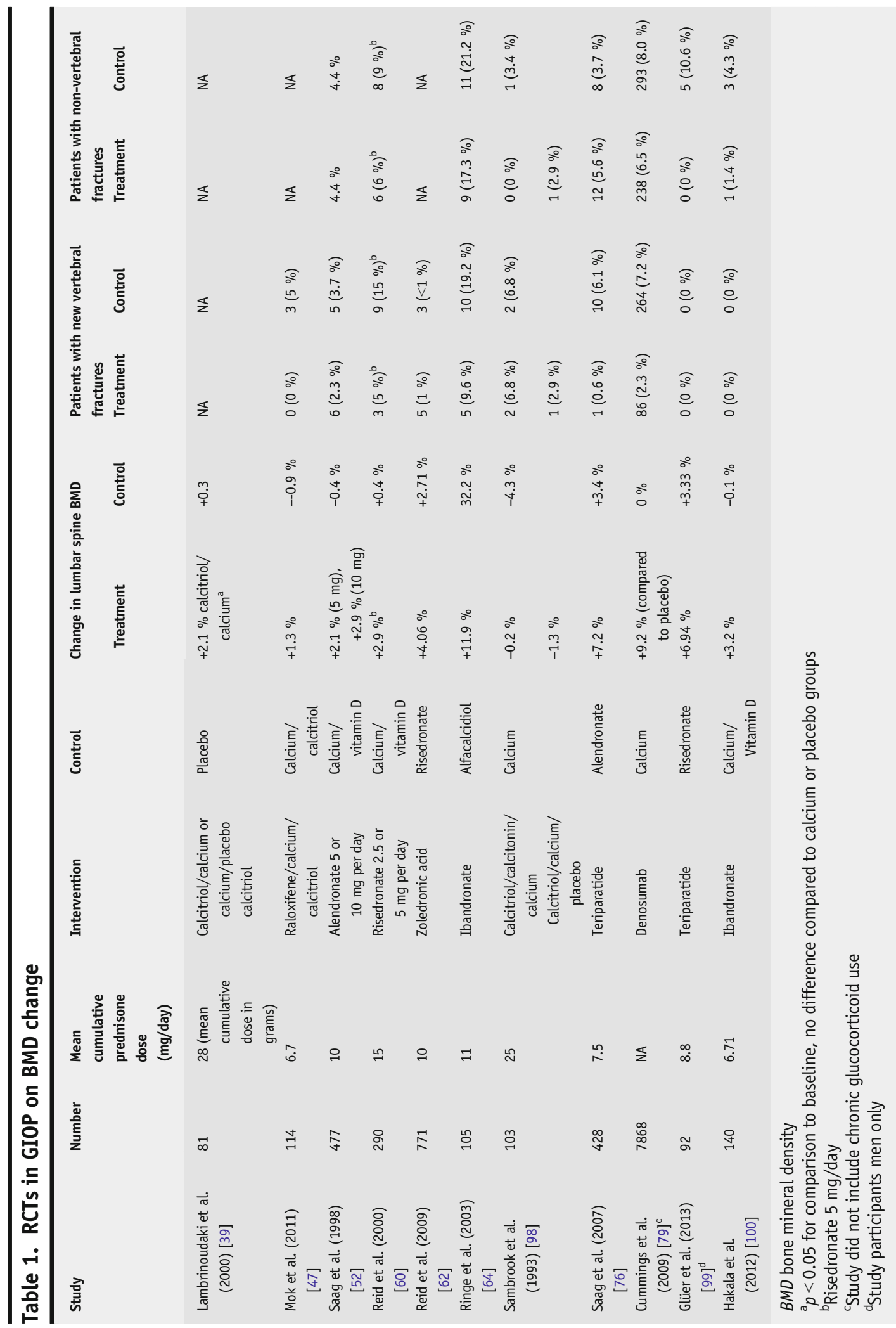


Raloxifene is a SERM which has been studied by Mok et al. for its prevention of bone loss in patients with SLE [46, 47]. In 2005, they compared raloxifene plus calcium to calcium alone and found preservation of spine and hip BMD in the raloxifene group with no significant increase in flares. In 2011, Mok et al. looked at efficacy in lupus patients on glucocorticoids comparing raloxifene to placebo with both groups also receiving calcium and vitamin D. Lumbar spine BMD was significantly increased in the raloxifene group compared to baseline. Raloxifene is associated with an increased risk of thromboembolism, which is a concern in a lupus population. In the 2010 ACR recommendations for GIOP, it was not one of the recommended therapeutic interventions.

DHEA is an androgen that may play a role in bone metabolism. Several studies have examined the use of DHEA (prasterone) at a dose of $200 \mathrm{mg} /$ day in SLE patients. One trial demonstrated that prasterone provided mild protection against bone loss in female SLE patients on chronic steroids [48]. However, in the premenopausal population, other trials have shown no effect on BMD and even potentially worsening of lipid profile with decreased HDL levels [49, 50].

- Bisphosphonates

Bisphosphonates are a class of antiresorptive agents that remain a firstline therapy for prevention and treatment of osteoporosis (see Fig. 1). A meta-analysis conducted by Feng et al. [51 $\bullet$ examined bisphosphonate efficacy in fracture prevention and bone mass preservation in rheumatic patients. They found that bisphosphonates preserve BMD and decrease vertebral fractures for this population with increased efficacy when used for prevention and treatment. Of the bisphosphonates, alendronate, risedronate, and zoledronic acid have been approved by the ACR for use in GIOP [24].

Alendronate has been studied in multiple trials that included SLE patients with all demonstrating its efficacy. Saag et al. conducted a randomized controlled trial (RCT) of alendronate (2.5 vs 5 vs $10 \mathrm{mg}$ /

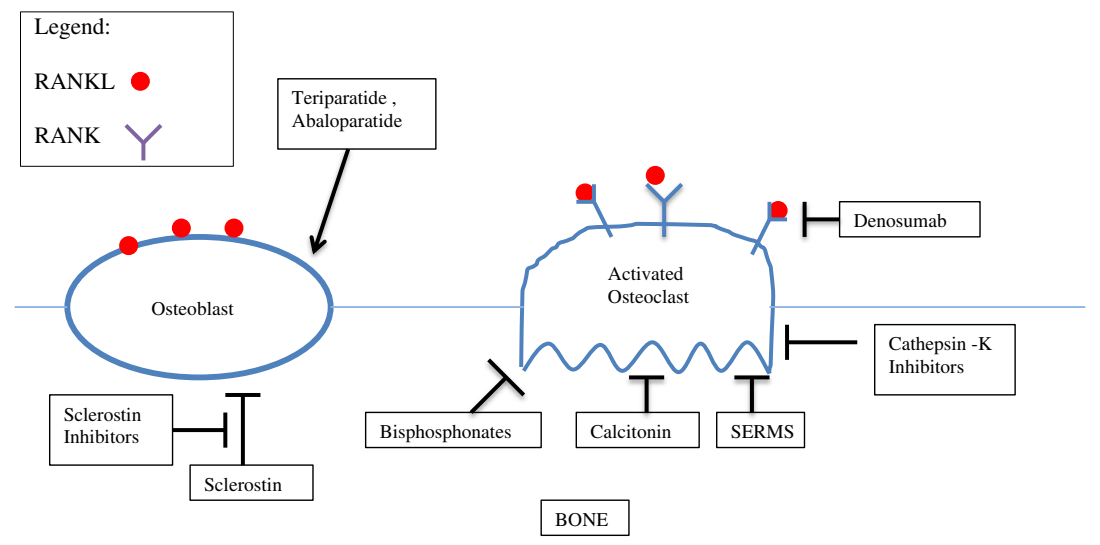

Fig. 1. Drug mechanism of action. 
day) vs placebo use in patients on long-term glucocorticoid therapy (SLE $10 \%$ of cohort) [52]. They found that 5 and $10 \mathrm{mg}$ of alendronate significantly increased BMD of the lumbar spine, trochanter, and femoral neck compared to placebo. Although fracture was not a primary outcome, the number of new vertebral fractures was less in the treatment group compared to placebo, but this did not meet statistical significance. A 2-year follow-up study by Adachi et al. demonstrated continued efficacy on prevention and treatment of GIOP with alendronate [53]. Similar results have been seen with alendronate in premenopausal SLE women on glucocorticoids [54, 55]. Studies have also shown superiority of alendronate compared to calcium and vitamin D [56-58]. The cost for 70-mg weekly generic can be as low as $\$ 78 /$ year [59].

Risedronate has also been shown to improve BMD in GIOP. Two RCTs with study populations including SLE compared risedronate to placebo in high-dose glucocorticoid therapy. Reid et al. found that $5 \mathrm{mg} /$ day risedronate increased $\mathrm{BMD}$ at the lumbar spine, trochanter, and femoral neck (SLE $7.6 \%$ of cohort) [60]. Additionally, a reduction in the incidence of vertebral fracture was observed, although this result did not meet statistical significance. Mok et al. examined risedronate plus calcium vs placebo plus calcium and found improvement in lumbar spine BMD, but a decrease in hip BMD (SLE $52 \%$ of cohort) [61]. Cost for generic risedronate $35 \mathrm{mg}$ a week is $\$ 1200 /$ year [59].

Zoledronic acid is an intravenous bisphosphonate administered once a year. Reid et al. conducted a randomized controlled non-inferiority study that examined zoledronic acid vs daily risedronate in $833 \mathrm{pa}-$ tients on glucocorticoids of whom $13 \%$ had SLE [62]. The study found that zoledronic acid was non-inferior and superior to risedronate at lumbar spine, femoral neck, trochanter, and total hip BMD for both prevention and treatment of GIOP. No difference was found between the two groups for frequency of new vertebral fractures. A recent study by Sambrook et al. compared zoledronic acid and risedronate in GIOP for men only and similarly found that zoledronic acid was superior to risedronate with increased lumbar spine and total hip BMD for both prevention and treatment, although no difference was observed at the femoral neck [63]. Estimated cost of zoledronic acid $5 \mathrm{mg}$ is $\$ 1000$ / year, which does not take into account intravenous administration fees [59].

Ibandronate is a bisphosphonate that comes in both oral and intravenous (IV) formulations. Ringe et al. compared daily oral alfacalcidol to every 3-month IV ibandronate in treatment of GIOP, which demonstrated increased lumbar spine and femoral neck BMD [64]. The ibandronate arm had a $50 \%$ reduction in new vertebral fractures compared to the alfacaldiol arm, although this was not significant. At the time of the manuscript preparation, ibandronate $150 \mathrm{mg}$ monthly was as low as $\$ 564 /$ year [59].

The use of bisphosphonates in premenopausal women is controversial given the long half-life of the drug and its potential harm to a fetus. 
Bisphosphonates have a half-life of years; therefore, women of childbearing age who have used bisphosphonates still risk exposure of the drug to the fetus even if the drug was discontinued years ago [65•]. Bisphosphonates are pregnancy class $\mathrm{C}$ and may be teratogenic. Animal studies in pregnant rats who were exposed to large doses of bisphosphonates (more than human doses) showed protracted deliveries thought to be caused by hypocalcemia and fetal bone growth retardation $[66,67]$. Bisphosphonates should be used with caution in premenopausal women given the lack of data regarding safety in pregnancy; if they are used, a risk benefit discussion with the patient is advised.

Safety issues of bisphosphonates include osteonecrosis of the jaw, atypical hip fractures, gastrointestinal side effects, and concern for esophageal cancer. It is important to note though that although physicians and patients should be aware of these potential side effects, the incidence is small and the data suggests that the benefit of bisphosphonates outweighs the risks. For example, one study found the typical hip fracture incidence in patients on bisphosphonates to be $463 / 100,000$ person-years, whereas the incidence for atypical femur fracture was 1.78/100,000 person-years [68]. The incidence of bisphosphonate-related osteonecrosis of the jaw is less well known but has been estimated between 0.028 and $4.3 \%$ [69]. Ideal duration of bisphosphonate therapy is unknown and debated. The idea of a "drug holiday" after 3 to 5 years of therapy has arisen with results from the FLEX trial and extension of HORIZON trial, both suggesting that discontinuation of bisphosphonate therapy does not increase the risk of fracture [70, 71]. However, this may not apply to high-risk SLE patients with osteoporosis, previous fracture, and on chronic glucocorticoids [72].

- Calcitonin

Calcitonin is a naturally occurring peptide hormone with antiresorptive properties that has been used in osteoporosis. Although trials have not been done specifically examining SLE and calcitonin, multiple studies have looked at GIOP and calcitonin. A Cochrane review assessing the efficacy of calcitonin for treatment and prevention of GIOP demonstrated preservation in lumbar BMD at 12 months, but not at 24 months compared to placebo [73]. One study found that alendronate was significantly better than intranasal calcitonin at increasing BMD and decreasing bone turnover [74]. There is also a concern for increased risk of malignancy such as basal cell carcinoma and prostate cancer, although the data is not strong for a causal relationship [75]. For these reasons and with the development of more efficacious drugs, calcitonin is not considered as first-line therapy for the treatment of osteoporosis. Intranasal calcitonin costs about \$540/year [59].

- Teriparatide

Teriparatide is an anabolic agent comprised of recombinant human parathyroid hormone. Its use is primarily in high-risk postmenopausal women and men over age 50 with a 10 -year risk of a major 
osteoporotic fracture greater than or equal to $20 \%$ [24, 25].

Teriparatide has been shown to significantly increase BMD and decrease number of vertebral fractures in GIOP. A RCT by Saag et al. (SLE $11 \%$ of cohort) compared alendronate to teriparatide and found increased lumbar spine and total hip BMD ( $p<0.001$ for both) as well as significantly fewer vertebral fractures than alendronate [76, 77]. Teriparatide should not be prescribed to patients at increased risk of osteosarcoma as there has been a dose- and duration-dependent elevated risk for development of osteosarcoma with this medication in animal models [78]. Main side effects include transient hypercalcemia, GI upset, and weakness. Dosage is $20 \mu$ g subcutaneous (SQ)/daily for no longer than 2 years. Cost is $\$ 24,240$ /year with some financial assistance programs available for those who qualify [59].

- Denosumab

Denosumab is a monoclonal antibody against receptor activator of nuclear factor kappa-B ligand (RANKL) and is a newer agent for osteoporosis treatment. In the Fracture Reduction Evaluation of Denosumab in Osteoporosis every 6 Months (FREEDOM) trial, denosumab was shown to reduce the risk of fracture (vertebral, nonvertebral, and hip) and increase lumbar and hip BMD [79]. Denosumab has also been shown to increase BMD significantly when compared to alendronate; however, a meta-analysis comparing fracture risk between denosumab and alendronate showed no difference [80, 81]. Efficacy of denosumab on GIOP and SLE populations has not specifically been studied. This would be interesting given the association with increased expression of RANKL with steroid use [82]. Side effects include hypocalcemia, osteonecrosis of the jaw, and atypical femur fractures $[83 \bullet \bullet, 84 \bullet \bullet]$. Concern for increased risk of infection has been raised, and given that RANK and RANKL are used in T cell proliferation and inhibition of RANKL may impair the immune response [85]. Overall incidence of infection was not increased in the denosumab arm in the FREEDOM trial; however, severe cellulitis was significantly increased compared to placebo [79]. Therefore, it would be prudent to exercise caution should the medication be used in immunosuppressed patients. Dosage is $60 \mathrm{mg}$ SQ every 6 months and can be used in renal insufficiency [86]. Two injections per year cost about $\$ 1800$ [59].

- Abaloparatide is a PTHrP analog similar to teriparatide which has shown promising results for increased BMD and reduction of fractures. In the phase II study by Leder et al. with 222 healthy postmenopausal women with osteoporosis [87], $80 \mu \mathrm{g} \mathrm{SQ/day} \mathrm{abaloparatide} \mathrm{showed}$ greater increase in lumbar spine and femoral neck BMD when compared to teriparatide and placebo. The recent phase III study evaluating fracture prevention compared to placebo and to teriparatide 
demonstrated reduced new vertebral fractures, non-vertebral, and clinical fractures compared to placebo. Abaloparatide also had a significantly lower incidence of hypercalcemia compared to teriparatide $[88 \bullet \bullet$.

- Odanacatib is a cathepsin $\mathrm{K}$ inhibitor that is an anticatabolic agent. Cathepsin $\mathrm{K}$ is a protease found primarily in lysosomes of osteoclasts that breaks down type I collagen (major component of bone matrix) in acidic environments $[89,90]$. Inhibition of cathepsin K blocks the collagenolytic action, thus not only stopping bone resorption but preserving bone formation $[88 \bullet \bullet, 89,90]$. Prior cathepsin K inhibitors under development were discontinued because of side effects. Odanacatib underwent a phase III fracture study (LOFT) [91•], in which all primary end points (radiographically detected vertebral, clinical hip, and clinical non-vertebral fractures) were met early. A significant relative risk reduction of new and worsening vertebral fractures, hip fractures, and clinical non-vertebral and vertebral fractures was seen with odanacatib compared to placebo. Additionally, BMD was increased in lumbar spine and total hip.

- Romosozumab, blosozumab, and BPS804 are sclerostin inhibitors which serve to block sclerostin resulting in increased osteoblast activity

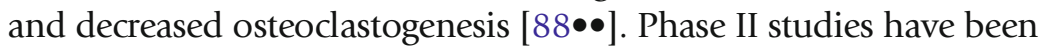
completed for all three drugs. Romosozumab and blosozumab had increased BMD at the lumbar spine, total hip, and femoral neck excluding distal radius $[92 \bullet, 93]$. BPS804 phase II results have not yet been released. Phase III trial assessing efficacy for fracture reduction for romosozumab is underway.

Guidelines for prevention and treatment of low BMD in the pediatric population are lacking especially for GIOP, given the limited treatment options and lack of studies in this population. In general, vitamin D and calcium supplementation is advised, although daily supplementation in the absence of deficiency has not shown a benefit in trials for other chronic inflammatory diseases [94]. Other preventative strategies include physical activity and weight-bearing exercise. One study surveyed pediatric rheumatologists across North America and found that most respondents prescribed calcium and vitamin D supplementation. However, in patients with osteoporosis (based on BMD), only at most half prescribed a bisphosphonate [95]. There have been some studies demonstrating the utility of bisphosphonates for children with osteoporosis. Bianchi et al. [96] included 38 children with low bone mass treated with alendronate compared to 38 children with the same diffuse connective tissue diseases (SLE $31 \%$ of cohort) as the study group but in a less severe form. They found a significant increase in lumbar spine BMD compared to controls. A recent Cochrane review [97] assessing bisphosphonate treatment for children with secondary osteoporosis concluded that there was not enough evidence for bisphosphonate use as standard therapy. Further studies are required for prevention and treatment guidelines in the pediatric population at risk for osteoporosis and fractures. 


\section{Compliance with Ethical Standards}

\section{Conflict of Interest}

Tracy Lin declares that she has no conflicts of interest. Jennifer Grossman reports that she has received support in the form of grants from Bristol Myers Squibb, Human Genome Science, Astra Zeneca, and UCB and has been on an advisory board for Genetech, outside the submitted work.

Human and Animal Rights and Informed Consent

This article does not contain any studies with human or animal subjects performed by any of the authors.

\section{References and Recommended Reading}

Papers of particular interest, published recently, have been highlighted as:

- Of importance

$\bullet$ Of major importance

1. Garcia-Carrasco M, Mendoza-Pinto C, Escarcega RO, Jimenez-Hernandez M, Etchegaray Morales I, Munguia Realpozo P, et al. Osteoporosis in patients with systemic lupus erythematosus. Isr Med Assoc J: IMAJ. 2009;11(8):486-91.

2. Sun YN, Feng XY, He L, Zeng LX, Hao ZM, Lv XH, et al. Prevalence and possible risk factors of low bone mineral density in untreated female patients with systemic lupus erythematosus. BioMed Res Int. 2015;2015:510514.

3. Panopalis P, Yazdany J. Bone health in systemic lupus erythematosus. Curr Rheumatol Rep. 2009;11(3):17784.

4. Di Munno O, Mazzantini M, Delle Sedie A, Mosca M, Bombardieri S. Risk factors for osteoporosis in female patients with systemic lupus erythematosus. Lupus. 2004;13(9):724-30.

5. Gladman DD, Urowitz $\mathrm{MB}$, Goldsmith $\mathrm{CH}$, Fortin $\mathrm{P}$, Ginzler E, Gordon C, et al. The reliability of the Systemic Lupus International Collaborating Clinics/ American College of Rheumatology damage index in patients with systemic lupus erythematosus. Arthritis Rheum. 1997;40(5):809-13.

6. Zonana-Nacach A, Barr SG, Magder LS, Petri M. Damage in systemic lupus erythematosus and its association with corticosteroids. Arthritis Rheum. 2000;43(8):1801-8.

7. Vellucci R, Mediati RD, Ballerini G. Use of opioids for treatment of osteoporotic pain. Clinical Cases Miner Bone Metab : Off J Ital Soc Osteoporosis Miner Metab Skelet Dis. 2014;11(3):173-6.

8. Bentler SE, Liu L, Obrizan M, Cook EA, Wright KB, Geweke JF, et al. The aftermath of hip fracture: discharge placement, functional status change, and mortality. Am J Epidemiol. 2009;170(10):1290-9.

9. Wolinsky FD, Fitzgerald JF, Stump TE. The effect of hip fracture on mortality, hospitalization, and functional status: a prospective study. Am J Public Health. 1997;87(3):398-403.

10. Grossman JM. Osteoporosis prevention. Curr Opin Rheumatol. 2011;23(2):203-10.

11. Becker A, Fischer R, Scherbaum WA, Schneider M. Osteoporosis screening in systemic lupus erythematosus: impact of disease duration and organ damage. Lupus. 2001;10(11):809-14.

12. Bhattoa HP, Bettembuk P, Balogh A, Szegedi G, Kiss E. Bone mineral density in women with systemic lupus erythematosus. Clin Rheumatol. 2002;21(2):135-41.

13. Kipen Y, Buchbinder R, Forbes A, Strauss B, Littlejohn $\mathrm{G}$, Morand E. Prevalence of reduced bone mineral density in systemic lupus erythematosus and the role of steroids. J Rheumatol. 1997;24(10):1922-9.

14. Mok CC, Mak A, Ma KM. Bone mineral density in postmenopausal Chinese patients with systemic lupus erythematosus. Lupus. 2005;14(2):106-12.

15. Bultink IE. Osteoporosis and fractures in systemic lupus erythematosus. Arthritis Care Res. 2012;64(1):2-8.

16. Sen D, Keen RW. Osteoporosis in systemic lupus erythematosus: prevention and treatment. Lupus. 2001;10(3):227-32.

17. Tang XL, Griffith JF, Qin L, Hung VW, Kwok AW, Zhu TY, et al. SLE disease per se contributes to deterioration in bone mineral density, microstructure and bone strength. Lupus. 2013;22(11):1162-8.

18. Pineau CA, Urowitz MB, Fortin PJ, Ibanez D, Gladman DD. Osteoporosis in systemic lupus erythematosus: factors associated with referral for bone mineral density studies, prevalence of osteoporosis and factors associated with reduced bone density. Lupus. 2004;13(6):436-41.

19. Jacobs J, Korswagen LA, Schilder AM, van Tuyl LH, Dijkmans BA, Lems WF, et al. Six-year follow-up study of bone mineral density in patients with systemic lupus erythematosus. Osteoporos Int : J Estab Result Coop 
Eur Found Osteoporos Natl Osteoporos Found U S A. 2013;24(6):1827-33.

This is one of the longer and larger studies published recently to evaluate osteoporosis risk factor for lupus patients in a cohort with a mean age of 39 .

20. FRAX. WHO Fracture Risk Assessment Tool. URL: http://shef.ac.uk/FRAX/

21. Mak A, Lim JQ, Liu Y, Cheak AA, Ho RC. Significantly higher estimated 10-year probability of fracture in lupus patients with bone mineral density comparable to that of healthy individuals. Rheumatol Int. 2013;33(2):299-307.

This study identifies an increased fracture risk in SLE.

22. van Staa TP, Leufkens HG, Abenhaim L, Zhang B, Cooper C. Oral corticosteroids and fracture risk: relationship to daily and cumulative doses. Rheumatology. 2000;39(12):1383-9.

23. Formiga F, Moga I, Nolla JM, Pac M, Mitjavila F, RoigEscofet D. Loss of bone mineral density in premenopausal women with systemic lupus erythematosus. Ann Rheum Dis. 1995;54(4):274-6.

24. Grossman JM, Gordon R, Ranganath VK, Deal C, Caplan L, Chen W, et al. American College of Rheumatology 2010 recommendations for the prevention and treatment of glucocorticoid-induced osteoporosis. Arthritis Care Res. 2010;62(11):1515-26.

25. Chugh PK. Management of women with systemic lupus erythematosus. Maturitas. 2013;75(3):207-14.

26. Lane NE. Therapy insight: osteoporosis and osteonecrosis in systemic lupus erythematosus. Nat Clin Pract Rheumatol. 2006;2(10):562-9.

27. Bonaiuti D, Shea B, Iovine R, Negrini S, Robinson V, Kemper HC, et al. Exercise for preventing and treating osteoporosis in postmenopausal women. Cochrane Database Syst Rev. 2002;3:CD000333.

28. Cummings SR, Nevitt MC, Browner WS, Stone K, Fox KM, Ensrud KE, et al. Risk factors for hip fracture in white women. Study of Osteoporotic Fractures Research Group. N Engl J Med.

1995;332(12):767-73.

29. Kipen Y, Briganti E, Strauss B, Will R, Littlejohn G, Morand E. Three year follow up of bone mineral density change in premenopausal women with systemic lupus erythematosus. J Rheumatol. 1999;26(2):310-7.

30. Kanis JA, Johnell O, Oden A, Johansson H, De Laet C, Eisman JA, et al. Smoking and fracture risk: a metaanalysis. Osteoporos Int : J Estab Result Coop Eur Found Osteoporos Natl Osteoporos Found U S A. 2005;16(2):155-62.

31. Vestergaard P, Mosekilde L. Fracture risk associated with smoking: a meta-analysis. J Intern Med. 2003;254(6):572-83.

32. Ward KD, Klesges RC. A meta-analysis of the effects of cigarette smoking on bone mineral density. Calcif Tissue Int. 2001;68(5):259-70.

33. Felson DT, Zhang Y, Hannan MT, Kannel WB, Kiel DP. Alcohol intake and bone mineral density in elderly men and women. The Framingham Study. Am J Epidemiol. 1995;142(5):485-92.
34. Ilich JZ, Brownbill RA, Tamborini L, Crncevic-Orlic Z. To drink or not to drink: how are alcohol, caffeine and past smoking related to bone mineral density in elderly women? J Am Coll Nutr. 2002;21(6):536-44.

35. Grainge MJ, Coupland CA, Cliffe SJ, Chilvers CE, Hosking DJ. Cigarette smoking, alcohol and caffeine consumption, and bone mineral density in postmenopausal women. The Nottingham EPIC Study Group. Osteoporos Int : J Estab Result Coop Eur Found Osteoporos Natl Osteoporos Found U S A. 1998;8(4):355-63.

36. Mok CC. Vitamin D and systemic lupus erythematosus: an update. Expert Rev Clin Immunol. 2013;9(5):45363.

This is an excellent review on the effects of vitamin D on lupus and bone health.

37. Sanguesa Gomez C, Flores Robles BJ, Andreu JL. Bone health, vitamin D and lupus. Reumatol Clin. 2015;11(4):232-6.

38. Adachi JD, Bensen WG, Bianchi F, Cividino A, Pillersdorf S, Sebaldt RJ, et al. Vitamin D and calcium in the prevention of corticosteroid induced osteoporosis: a 3 year follow up. J Rheumatol. 1996;23(6):995-1000.

39. Lambrinoudaki I, Chan DT, Lau CS, Wong RW, Yeung SS, Kung AW. Effect of calcitriol on bone mineral density in premenopausal Chinese women taking chronic steroid therapy. A randomized, double blind, placebo controlled study. J Rheumatol. 2000;27(7):1759-65.

40. Singh A, Kamen DL. Potential benefits of vitamin D for patients with systemic lupus erythematosus. Dermato Endocrinol. 2012;4(2):146-51.

41. Wang X, Chen H, Ouyang Y, Liu J, Zhao G, Bao W, et al. Dietary calcium intake and mortality risk from cardiovascular disease and all causes: a meta-analysis of prospective cohort studies. BMC Med. 2014;12:158.

42. Bolland MJ, Avenell A, Baron JA, Grey A, MacLennan GS, Gamble GD, et al. Effect of calcium supplements on risk of myocardial infarction and cardiovascular events: meta-analysis. BMJ. 2010;341:c3691.

43. Bhattoa HP, Bettembuk P, Balogh A, Szegedi G, Kiss E. The effect of 1-year transdermal estrogen replacement therapy on bone mineral density and biochemical markers of bone turnover in osteopenic postmenopausal systemic lupus erythematosus patients: a randomized, double-blind, placebo-controlled trial. Osteoporos Int: J Estab Result Coop Eur Found Osteoporos Natl Osteoporos Found U S A. 2004;15(5):396-404.

44. Kung AW, Chan TM, Lau CS, Wong RW, Yeung SS. Osteopenia in young hypogonadal women with systemic lupus erythematosus receiving chronic steroid therapy: a randomized controlled trial comparing calcitriol and hormonal replacement therapy. Rheumatology. 1999;38(12):1239-44.

45. Rossouw JE, Anderson GL, Prentice RL, LaCroix AZ, Kooperberg C, Stefanick ML, et al. Risks and benefits of estrogen plus progestin in healthy postmenopausal women: principal results from the Women's Health 
Initiative randomized controlled trial. JAMA. 2002;288(3):321-33.

46. Mok CC, To CH, Mak A, Ma KM. Raloxifene for postmenopausal women with systemic lupus erythematosus: a pilot randomized controlled study. Arthritis Rheum. 2005;52(12):3997-4002.

47. Mok CC, Ying KY, To CH, Ho LY, Yu KL, Lee HK, et al. Raloxifene for prevention of glucocorticoid-induced bone loss: a 12-month randomised double-blinded placebo-controlled trial. Ann Rheum Dis. 2011;70(5):778-84.

48. Sanchez-Guerrero J, Fragoso-Loyo HE, Neuwelt CM, Wallace DJ, Ginzler EM, Sherrer YR, et al. Effects of prasterone on bone mineral density in women with active systemic lupus erythematosus receiving chronic glucocorticoid therapy. J Rheumatol. 2008;35(8):1567-75.

49. Hartkamp A, Geenen R, Godaert GL, Bijl M, Bijlsma JW, Derksen RH. The effect of dehydroepiandrosterone on lumbar spine bone mineral density in patients with quiescent systemic lupus erythematosus. Arthritis Rheum. 2004;50(11):3591-5.

50. Marder W, Somers EC, Kaplan MJ, Anderson MR, Lewis EE, McCune WJ. Effects of prasterone

(dehydroepiandrosterone) on markers of cardiovascular risk and bone turnover in premenopausal women with systemic lupus erythematosus: a pilot study. Lupus. 2010;19(10):1229-36.

51.• Feng Z, Zeng S, Wang Y, Zheng Z, Chen Z. Bisphosphonates for the prevention and treatment of osteoporosis in patients with rheumatic diseases: a systematic review and meta-analysis. PLoS One. 2013;8(12):e80890.

This is a meta-analysis of 20 studies of bisphosphonates in patients with rheumatic diseases supporting the efficacy of this treatment for osteoporosis management.

52. Saag KG, Emkey R, Schnitzer TJ, Brown JP, Hawkins F, Goemaere $\mathrm{S}$, et al. Alendronate for the prevention and treatment of glucocorticoid-induced osteoporosis. Glucocorticoid-Induced Osteoporosis Intervention Study Group. N Engl J Med. 1998;339(5):292-9.

53. Adachi JD, Saag KG, Delmas PD, Liberman UA, Emkey $\mathrm{RD}$, Seeman E, et al. Two-year effects of alendronate on bone mineral density and vertebral fracture in patients receiving glucocorticoids: a randomized, double-blind, placebo-controlled extension trial. Arthritis Rheum. 2001;44(1):202-11.

54. Yeap SS, Fauzi AR, Kong NC, Halim AG, Soehardy Z, Rahimah I, et al. A comparison of calcium, calcitriol, and alendronate in corticosteroid-treated premenopausal patients with systemic lupus erythematosus. J Rheumatol. 2008;35(12):2344-7.

55. Okada Y, Nawata M, Nakayamada S, Saito K, Tanaka Y. Alendronate protects premenopausal women from bone loss and fracture associated with high-dose glucocorticoid therapy. J Rheumatol. 2008;35(11):2249_ 54.

56. de Nijs RN, Jacobs JW, Lems WF, Laan RF, Algra A, Huisman AM, et al. Alendronate or alfacalcidol in glucocorticoid-induced osteoporosis. N Engl J Med. 2006;355(7):675-84.

57. Sambrook PN, Kotowicz M, Nash P, Styles CB, Naganathan V, Henderson-Briffa KN, et al. Prevention and treatment of glucocorticoid-induced osteoporosis: a comparison of calcitriol, vitamin D plus calcium, and alendronate plus calcium. J Bone Miner Res: Off J Am Soc Bone Miner Res. 2003;18(5):919-24.

58. Takeda S, Kaneoka H, Saito T. Effect of alendronate on glucocorticoid-induced osteoporosis in Japanese women with systemic autoimmune diseases: versus alfacalcidol. Modern Rheumatol : Jpn Rheum Assoc. 2008;18(3):271-6.

59. GoodRx. URL: http://www.goodrx.com. November 17, 2015.

60. Reid DM, Hughes RA, Laan RF, Sacco-Gibson NA, Wenderoth DH, Adami S, et al. Efficacy and safety of daily risedronate in the treatment of corticosteroidinduced osteoporosis in men and women: a randomized trial. European Corticosteroid-Induced Osteoporosis Treatment Study. J Bone Miner Res : Off J Am Soc Bone Miner Res. 2000;15(6):1006-13.

61. Mok CC, Tong KH, To CH, Siu YP, Ma KM.

Risedronate for prevention of bone mineral density loss in patients receiving high-dose glucocorticoids: a randomized double-blind placebo-controlled trial. Osteoporos Int : J Estab Result Coop Eur Found Osteoporos Natl Osteoporos Found U S A. 2008;19(3):357-64.

62. Reid DM, Devogelaer JP, Saag K, Roux C, Lau CS, Reginster JY, et al. Zoledronic acid and risedronate in the prevention and treatment of glucocorticoidinduced osteoporosis (HORIZON): a multicentre, double-blind, double-dummy, randomised controlled trial. Lancet. 2009;373(9671):1253-63.

63. Sambrook PN, Roux C, Devogelaer JP, Saag K, Lau CS, Reginster JY, et al. Bisphosphonates and glucocorticoid osteoporosis in men: results of a randomized controlled trial comparing zoledronic acid with risedronate. Bone. 2012;50(1):289-95.

64. Ringe JD, Dorst A, Faber H, Ibach K, Preuss J. Threemonthly ibandronate bolus injection offers favourable tolerability and sustained efficacy advantage over two years in established corticosteroid-induced osteoporosis. Rheumatology. 2003;42(6):743-9.

65. Suresh E, Pazianas M, Abrahamsen B. Safety issues with bisphosphonate therapy for osteoporosis. Rheumatology. 2014;53(1):19-31.

A good review for side effects of bisphosphonates.

66. Patlas N, Golomb G, Yaffe P, Pinto T, Breuer E, Ornoy A. Transplacental effects of bisphosphonates on fetal skeletal ossification and mineralization in rats. Teratology. 1999;60(2):68-73.

67. Minsker DH, Manson JM, Peter CP. Effects of the bisphosphonate, alendronate, on parturition in the rat. Toxicol Appl Pharmacol. 1993;121(2):217-23.

68. Dell RM, Adams AL, Greene DF, Funahashi TT, Silverman SL, Eisemon EO, et al. Incidence of atypical nontraumatic diaphyseal fractures of the femur. J Bone 
Miner Res : Off J Am Soc Bone Miner Res. 2012;27(12):2544-50.

69. Solomon DH, Mercer E, Woo SB, Avorn J, Schneeweiss $\mathrm{S}$, Treister N. Defining the epidemiology of bisphosphonate-associated osteonecrosis of the jaw: prior work and current challenges. Osteoporos Int : J Estab Res Coop Eur Found Osteoporos Natl Osteoporos Found U S A. 2013;24(1):237-44.

70. Black DM, Schwartz AV, Ensrud KE, Cauley JA, Levis S, Quandt SA, et al. Effects of continuing or stopping alendronate after 5 years of treatment: the Fracture Intervention Trial Long-term Extension (FLEX): a randomized trial. JAMA. 2006;296(24):2927-38.

71. Black DM, Reid IR, Boonen S, Bucci-Rechtweg C, Cauley JA, Cosman F, et al. The effect of 3 versus 6 years of zoledronic acid treatment of osteoporosis: a randomized extension to the HORIZON-Pivotal Fracture Trial (PFT). J Bone Miner Res : Off J Am Soc Bone Miner Res. 2012;27(2):243-54.

72. McClung M, Harris ST, Miller PD, Bauer DC, Davison KS, Dian L, et al. Bisphosphonate therapy for osteoporosis: benefits, risks, and drug holiday. Am J Med. 2013;126(1):13-20.

73. Cranney A, Welch V, Adachi JD, Homik J, Shea B, Suarez-Almazor ME, et al. Calcitonin for the treatment and prevention of corticosteroid-induced osteoporosis. Cochrane Database Syst Rev. 2000;2:CD001983.

74. Tascioglu F, Colak O, Armagan O, Alatas O, Oner C. The treatment of osteoporosis in patients with rheumatoid arthritis receiving glucocorticoids: a comparison of alendronate and intranasal salmon calcitonin. Rheumatol Int. 2005;26(1):21-9.

75. Overman RA, Borse M, Gourlay ML. Salmon calcitonin use and associated cancer risk. Ann Pharmacother. 2013;47(12):1675-84.

76. Saag KG, Shane E, Boonen S, Marin F, Donley DW, Taylor KA, et al. Teriparatide or alendronate in glucocorticoid-induced osteoporosis. N Engl J Med. 2007;357(20):2028-39.

77. Saag KG, Zanchetta JR, Devogelaer JP, Adler RA, Eastell $\mathrm{R}$, See $\mathrm{K}$, et al. Effects of teriparatide versus alendronate for treating glucocorticoid-induced osteoporosis: thirty-six-month results of a randomized, doubleblind, controlled trial. Arthritis Rheum. 2009;60(11):3346-55.

78. Vahle JL, Sato M, Long GG, Young JK, Francis PC, Engelhardt JA, et al. Skeletal changes in rats given daily subcutaneous injections of recombinant human parathyroid hormone (1-34) for 2 years and relevance to human safety. Toxicol Pathol. 2002;30(3):312-21.

79. Cummings SR, San Martin J, McClung MR, Siris ES, Eastell R, Reid IR, et al. Denosumab for prevention of fractures in postmenopausal women with osteoporosis. N Engl J Med. 2009;361(8):756-65.

80. Brown JP, Prince RL, Deal C, Recker RR, Kiel DP, de Gregorio LH, et al. Comparison of the effect of denosumab and alendronate on BMD and biochemical markers of bone turnover in postmenopausal women with low bone mass: a randomized, blinded, phase 3 trial. J Bone Miner Res : Off J Am Soc Bone Miner Res. 2009;24(1):153-61.

81. Lin T, Wang C, Cai XZ, Zhao X, Shi MM, Ying ZM, et al. Comparison of clinical efficacy and safety between denosumab and alendronate in postmenopausal women with osteoporosis: a meta-analysis. Int J Clin Pract. 2012;66(4):399-408.

82. Hofbauer LC, Zeitz U, Schoppet M, Skalicky M, Schuler $\mathrm{C}$, Stolina M, et al. Prevention of glucocorticoidinduced bone loss in mice by inhibition of RANKL. Arthritis Rheum. 2009;60(5):1427-37.

83.• Komm BS, Morgenstern D, AY L, Jenkins SN. The safety and tolerability profile of therapies for the prevention and treatment of osteoporosis in postmenopausal women. Expert Rev Clin Pharmacol. 2015;20:1-16.

An excellent review on side effects of osteoporosis therapies.

84.• Papapoulos S, Lippuner K, Roux C, Lin CJ, Kendler DL, Lewiecki EM, et al. The effect of 8 or 5 years of denosumab treatment in postmenopausal women with osteoporosis: results from the FREEDOM extension study. Osteoporos Int : J Estab Result Coop Eur Found Osteoporosis Natl Osteoporosis Found U S A. 2015 Jul 23.

This is an important recent publication of the extension of the pivotal denosumab trial.

85. Martin TJ. Paracrine regulation of osteoclast formation and activity: milestones in discovery. J Musculoskelet Neuronal Interact. 2004;4(3):243-53.

86. Jamal SA, Ljunggren O, Stehman-Breen C, Cummings SR, McClung MR, Goemaere S, et al. Effects of denosumab on fracture and bone mineral density by level of kidney function. J Bone Miner Res : Off J Am Soc Bone Miner Res. 2011;26(8):1829-35.

87. Leder BZ, O'Dea LS, Zanchetta JR, Kumar P, Banks K, McKay K, et al. Effects of abaloparatide, a human parathyroid hormone-related peptide analog, on bone mineral density in postmenopausal women with osteoporosis. J Clin Endocrinol Metab. 2015;100(2):697706.

88.• Makras P, Delaroudis S, Anastasilakis AD. Novel therapies for osteoporosis. Metab Clin Exp. 2015;64(10):1199-214.

Up to date review on new and emerging therapies for osteoporosis.

89. Stoch SA, Wagner JA. Cathepsin K inhibitors: a novel target for osteoporosis therapy. Clin Pharmacol Ther. 2008;83(1):172-6.

90. Helali AM, Iti FM, Mohamed IN. Cathepsin K inhibitors: a novel target but promising approach in the treatment of osteoporosis. Curr Drug Targets. 2013;14(13):1591-600.

91. Bone HG, Dempster DW, Eisman JA, Greenspan SL, McClung MR, Nakamura T, et al. Odanacatib for the treatment of postmenopausal osteoporosis: development history and design and participant characteristics of LOFT, the Long-Term Odanacatib Fracture Trial. Osteoporos Int : J Estab Result Coop Eur Found Osteoporos Natl Osteoporos Found U S A. 2015;26(2):699-712. 
This is a promising novel therapy and novel target.

92.• McClung MR, Grauer A, Boonen S, Bolognese MA, Brown JP, Diez-Perez A, et al. Romosozumab in postmenopausal women with low bone mineral density. $\mathrm{N}$ Engl J Med. 2014;370(5):412-20.

This is a recently published study of a promising novel therapy.

93. Recker RR, Benson CT, Matsumoto T, Bolognese MA, Robins DA, Alam J, et al. A randomized, double-blind phase 2 clinical trial of blosozumab, a sclerostin antibody, in postmenopausal women with low bone mineral density. J Bone Miner Res : Off J Am Soc Bone Miner Res. 2015;30(2):216-24.

94. von Scheven E, Corbin KJ, Stagi S, Cimaz R.

Glucocorticoid-associated osteoporosis in chronic inflammatory diseases: epidemiology, mechanisms, diagnosis, and treatment. Curr Osteoporos Rep. 2014;12(3):289-99.

95. Soybilgic A, Tesher M, Wagner-Weiner L, Onel KB. A survey of steroid-related osteoporosis diagnosis, prevention and treatment practices of pediatric rheumatologists in North America. Pediatr Rheumatol Online J. 2014;12:24.

96. Bianchi ML, Cimaz R, Bardare M, Zulian F, Lepore L, Boncompagni A, et al. Efficacy and safety of alendronate for the treatment of osteoporosis in diffuse connective tissue diseases in children: a prospective multicenter study. Arthritis Rheum. 2000;43(9):19606.

97. Ward L, Tricco AC, Phuong P, Cranney A, Barrowman N, Gaboury I, et al. Bisphosphonate therapy for children and adolescents with secondary osteoporosis. Cochrane Database Syst Rev. 2007;4:CD005324.

98. Sambrook P, Birmingham J, Kelly P, Kempler S, Nguyen T, Pocock N, et al. Prevention of corticosteroid osteoporosis. A comparison of calcium, calcitriol, and calcitonin. N Engl J Med. 1993;328(24):1747-52.

99. Gluer CC, Marin F, Ringe JD, Hawkins F, Moricke R, Papaioannu N, et al. Comparative effects of teriparatide and risedronate in glucocorticoid-induced osteoporosis in men: 18-month results of the EuroGIOPs trial. J Bone Miner Res: Off J Am Soc Bone Miner Res. 2013;28(6):1355-68.

100. Hakala M, Kroger H, Valleala H, Hienonen-Kempas T, Lehtonen-Veromaa M, Heikkinen J, et al. Oncemonthly oral ibandronate provides significant improvement in bone mineral density in postmenopausal women treated with glucocorticoids for inflammatory rheumatic diseases: a 12-month, randomized, double-blind, placebo-controlled trial. Scand J Rheumatol. 2012;41(4):260-6. 